\title{
A problemática acerca da edição das notas saussurianas: um livro sem fim nem começo ou um livro de areia a la Borges?'1
}

\author{
Amanda Eloina Scherer ${ }^{2}$ \\ Maria Iraci Sousa Costa ${ }^{3}$
}

\section{Resumo}

O presente artigo desenvolve uma reflexão acerca do complexo processo de edição dos manuscritos saussurianos. A partir do estudo comparativo das notas de Ferdinand de Saussure publicadas em edicões diferentes, como por exemplo, as notas editadas por Robert Godel e publicadas na revista Cabiers (1954), as notas editadas por Simon Bouquet e Rudolf Engler (SAUSSURE, 2002) e também as notas editadas por René Amacker (2011), sustentamos que cada edição publicada se constitui como um livro de areia, no sentido poético e metafórico atribuido por Borges. Cada uma dessas publicações de notas manuscritas saussurianas apresenta uma ordem que the é própria, atribuindo ao texto uma linearidade singular. Como sabemos, apenas uma pequena parte dos manuscritos saussurianos foi editada e publicada e, mesmo essa pequena parte desdobra-se em sucessivas (re-)edições, cada qual dando um novo/outro (re-)arranjo, o que nos faz refletir acerca da ordem e da (im)possivel linearidade das notas saussurianas no tocante aos critérios dados pelos seus editores.

Palavras-chave: Livro de areia. Manuscritos saussurianos. Edições

\footnotetext{
${ }^{1}$ Este artigo, escrito a quatro mãos, é parte do estudo que estamos desenvolvendo, atualmente, no Centro de Documentação e Memória, na Universidade Federal de Santa Maria, através do projeto de pesquisa "História das Ideias Linguísticas no sul, parte IV".

2 Professora Titular de Linguística do Departamento de Letras Clássicas e Linguística e do Programa de PósGraduação em Letras da Universidade Federal de Santa Maria.

${ }^{3}$ Mestra e Doutora em Letras - Estudos Linguísticos pela Universidade Federal de Santa Maria, com estágio pós-doutoral na mesma instituição.
} 


\title{
Um ensejo particular ${ }^{4}$
}

\author{
"Disse-me que seu livro se chamava $\mathrm{O}$ livro de areia, porque nem o livro nem a \\ areia têm principio ou fim" \\ Jorge Luis Borges - O livro de areia
}

No conto "O livro de areia", de Jorge Luis Borges, o narrador nos conta a história de um livro que, a cada vez que era aberto, nunca era o mesmo. Esse livro parece ter chegado até o narrador de forma nada casual, como ele nos relata, e mais, parece ter sido escolhido para possuir o livro. Um vendedor de bíblias vai até a casa do narrador e, depois de alguma conversa, mostra-lhe o livro de areia, que o apresenta como um livro sagrado, e o oferece em troca de uma grande soma em dinheiro. O vendedor, por sua vez, diz que o adquiriu na Índia em troca de algumas moedas e de um exemplar da bíblia sagrada. Segundo o vendedor, o livro se chamava "livro de areia", porque o livro, assim como a areia, não tinha princípio nem fim. Vejamos o diálogo entre o narrador e o vendedor:

Pediu-me que procurasse a primeira folha. Apoiei a mão esquerda sobre a portada e abri com o polegar quase grudado ao índice. Tudo foi inútil: sempre se interpunham várias folhas entre a portada e a mão. Era como se brotassem do livro.

- Agora procure a final.

Também fracassei; mal consegui balbuciar com uma voz que não era a minha:

- Isto não pode ser. Sempre em voz baixa, o vendedor de bíblias disse:

- Não pode ser, mas é. O número de páginas deste livro é exatamente infinito. Nenhuma é a primeira: nenhuma, a última. Não sei por que são numeradas desse modo arbitrário. Talvez para dar a entender que os termos de uma série infinita admitem qualquer número.

Depois, como se pensasse em voz alta:

Se o espaço for infinito, estamos em qualquer ponto do espaço. Se o tempo for infinito, estamos em qualquer ponto do tempo" (BORGES, $2013, \mathrm{~s} / \mathrm{p})$.

O narrador, encantado e surpreso com o livro, decide comprá-lo e oferece uma certa quantia em dinheiro e um exemplar da bíblia, não qualquer exemplar, mas a Bíblia de Wycliffe, em letras góticas, primeira tradução da Vulgata Latina para o inglês médio, o que, segundo o narrador, possivelmente agradaria o vendedor que era presbiteriano.

Já em posse do livro, o narrador cogita guardá-lo no mesmo lugar onde guardava a Bíblia de Wycliffe, mas decidiu escondê-lo (sim, é esse o verbo usado pelo narrador) atrás

\footnotetext{
4 Essa reflexão teve início ainda no doutorado da Prof ${ }^{a}$. Maria Iraci Sousa Costa, durante seu Estágio Sanduíche (Capes 2013/2014) realizado no ITEM/ENS de Paris, sob coorientação da Prof ${ }^{a}$. Dr ${ }^{a}$. Irène Fenoglio.
} 
de alguns volumes de As mil e uma noites, o que lhe pareceu mais apropriado. Num primeiro momento, o livro de areia pareceu-lhe um presente divino, mas logo o narrador se deu conta de que havia se tornado prisioneiro do livro. O livro começou a parecer-lhe monstruoso e, então, o narrador decide livrar-se dele. Por receio de destruí-lo, decidiu perdê-lo entre milhares de exemplares de livros d(e um)a Biblioteca Nacional.

No conto de Borges, o livro de areia é apresentado pelo vendedor, ora como um livro sagrado ("Não vendo só bíblias. Posso lhe mostrar um livro sagrado que talvez lhe interesse"), ora como um livro diabólico ("Estou seguro de não ter ludibriado o nativo quando lhe dei a Palavra do Senhor em troca do seu livro diabólico"). E ao longo da narrativa, o livro de areia parece carregar outras contradições, especialmente no que toca à relação do livro com aquele que o possui. Num primeiro momento, quem o conhece parece tentado a possuí-lo, mas, num segundo momento, logo aquele que o possui, se dá conta de que é possuído pelo livro. O sujeito é tomado pela problemática da infinitude que faz o livro de areia parecer o objeto de desejo daqueles que o possuem. Um livro com um número infinito de páginas, sem começo nem fim e que, por mais que se tentasse, jamais se encontraria a primeira ou a última página. Um livro que abarcasse a infinitude de tudo. Quem teria escrito esse livro? A infinitude abarcaria tudo o que foi escrito e também o que virá a ser?

Não insistiremos mais em questionamentos que poderiam nos instigar à reflexão sobre a relação da infinitude, sob pena de cansar nosso leitor ou mesmo nos perder nos meandros de tantas sugestões. Além disso, não podemos nos deixar seduzir (ainda mais) nem influenciar pela escrita labiríntica de Borges como aquele que se deixa seduzir pelo canto da sereia. Para levarmos nosso leitor para fora desse labirinto, é preciso apontar-lhe o caminho. Pois bem: a temática de nosso artigo é a problemática da ordem das notas manuscritas saussurianas, bem como seu complexo processo de edição.

No presente artigo, sustentamos a ideia de que as edições dos manuscritos saussurianos se constituem enquanto um livro de areia, no sentido poético e metafórico atribuído por Borges. Para tanto, faz-se necessário retomar um pouco da história de exegese das publicações das edições dos manuscritos saussurianos, e não podemos deixar de considerar também, é claro, o Curso de Linguística Geral (CLG), que, como sabemos, foi editado a partir de um compilado de notas do mestre e de seus alunos referentes aos cursos ministrados em Genebra entre 1907 e 1911. Para ilustrar a problemática da ordem das 
notas saussurianas em edições diferentes, consideraremos as notas editadas e publicadas por Robert Godel na Revue Cabiers Ferdinand de Saussure (1954), a obra Écrits de Linguistique Générale (2002), editada por Rudolf Engler e Simon Bouquet, e também a edição suíça dos manuscritos saussurianos encontrados em 1996, Science du langage - De la double essence du langage, Édition des Écrits de linguistique générale établie par René Amacker. Em tais publicações, interessa-nos refletir acerca da organização atribuída a cada uma e à ordem dada a um dos manuscritos editados, entre outros.

\section{Um livro entre o sagrado e o diabólico}

Regarder la langue et se demander à quel moment précis une telle chose a «commencé» est aussi intelligent que de regarder le ruisseau de la montagne et de croire qu'en remontant on trouvera l'endroit précis où il a sa source. Des choses sans nombre établiront qu'à tout moment le RUISSEAU existe pendant qu'on dit qu'il nait, et que réciproquement il ne fait que naitre pendant qu'on (...) On peut discuter éternellement sur cette naissance, mais son plus grand caractère c'est d'être parfaitement le même que celui de la croissance (SAUSSURE, 2011, p. 60-61).

Da perspectiva discursiva que nos colocamos, a leitura é da ordem da interpretação e está relacionada às condições de produção do ato de ler. Todo o ato de ler implica uma ordem, implica um ponto de vista sobre, um olhar sobre algo que não nos deixa impune face aos sentidos. Sentidos e sujeito estão atrelados pelo dizer de si e do outro, atrelados a uma história pessoal e ao mesmo tempo, social e coletiva. Ler implica acima de tudo um ato político do sujeito face ao texto, face ao livro que se tem em mãos. E é nesse ato de ler que nos colocamos aqui, no efeito metafórico criado por Borges do livro de areia, quando projetamos uma possível leitura sobre os manuscritos, neste caso os de Saussure, na e da Universidade de Genebra.

Esse efeito metafórico à la Borges, de um livro de areia, nos foi lançado quando da primeira visita à Biblioteca de Genebra em que pudemos consultar o arquivo dos manuscritos saussurianos. Para nós, aquele primeiro contato com tal corpus de pesquisa, foi um grande momento de satisfação profissional e pessoal, mas também de descoberta de um real que nos é imposto cada vez mais na academia. Produzir conhecimento requer o ato de escrever; escrever requer ensaiar rascunhos, começar sem começo, terminar sem fim, construir um texto com tudo o que ele tem de um possível começo e de um fim ainda incerto. O rascunho tem um quê de diabólico e também de sagrado. De diabólico quando 
nosso pensamento vai nos pregando peças e nos encaminhando por trajetos tortuosos. $\mathrm{O}$ caminho de pensamento que ainda não está maduro, que precisamos escrever mais e sempre mais, está na infinitude ligada aos rascunhos, aos inúmeros rascunhos que vamos construindo ao longo de nossa vida acadêmica e que vão ficando ao léu como em uma gaveta dos guardados no dizer de Iberê Camargo (2009). De sagrado, quando estamos diante de um corpus imenso de um personagem histórico para a história da ciência linguística.

Uma das primeiras perguntas que nos fizemos, quando de nossa primeira visita, face à imensidão do arquivo colocado à prova frente aos nossos olhos, foi: por onde começar, onde estaria o ponto inicial? ... onde estaria o começo desse livro de areia que se delineava a nossa frente diante de um emaranhado de folhas ajustadas por números, por sinalizações outras que não estamos acostumados a tratar nas tradicionais bibliotecas públicas que frequentamos diariamente em nossa vida universitária? Teríamos um dia um final feliz ver editados todos os manuscritos do mestre genebrino? Nosso olhar nos fazia acreditar que tal conjunto de manuscritos parecia partilhar da mesma maldição que o livro de areia de Borges, uma vez que compreendemos que a instabilidade do sentido estava relacionada não só às condições produção em que tal corpus se inscreve, mas também nas condições em que a leitura de cada editor, de cada pesquisador, constitui-se a partir dele.

No caso do CLG, em especial, ao nosso ver, parecia carregar essa maldição, considerando as diferentes leituras projetadas sobre essa obra, bem como as diferentes recepções (PUECH, 2016) ao longo dos cem anos desde sua publicação. Há um século estamos falando de uma mesma obra sem que o autor (ou aquele a quem se atribui a autoria) tenha escrito uma linha sequer, e esse é um aspecto que merece também ser levado em conta.

Sabemos também que o CLG é conhecido entre os linguistas como a vulgata, assim como a bíblia é chamada entre os cristãos. Antes mesmo de ser associada ao texto sagrado, vulgata designa a forma latina abreviada de vulgata editio ou vulgata versio ou vulgata lectio, respectivamente "edição, tradução ou leitura de divulgação popular" - a versão mais difundida (ou mais aceita como autêntica) de um texto. A expressão latina vulgata entra para a posteridade como sinônimo de bíblia sagrada desde o acontecimento histórico da tradução do texto bíblico para o latim em torno do século IV a.C. Para os linguistas, a designação vulgata, para se referir ao CLG, é tomada no sentido de "versão mais difundida", realçando, 
desse modo, o papel dos editores, mas não deixa de retomar também um efeito de sentido de "texto sagrado", especialmente para aqueles linguistas saussurianos mais devotos.

E àqueles que questionam o CLG por não ter sido escrito e publicado por Saussure, os linguistas saussurianos mais devotos trazem logo esse argumento em resposta a essa provocação. Isaac Salum, por exemplo, no prefácio à edição brasileira do CLG, compara Saussure a Jesus e Sócrates:

\begin{abstract}
Saussure - como Sócrates e Jesus - é recebido de "segunda mão". Conhecemos Sócrates pelo que Xenofonte e Platão escreveram como sendo dele. O primeiro era muito pouco filósofo para entendê-lo, o segundo filósofo demais para não ir além dele, ambos distorcendo-o. Jesus nada escreveu senão na areia: seus ensinos são o que nos transmitiram seus discípulos, alguns dos quais não foram testemunhas oculares (SALUM, Prefácio do CLG in SAUSSURE, 2006, p. XVI).
\end{abstract}

Quando se trata de defender Saussure, os linguistas saussurianos não economizam nos argumentos e tampouco na modéstia. Jürgen Trabant (2005), por sua vez, que intitula seu texto Faut-il défendre Saussure contre ses amateurs?, jocosamente se pergunta sobre a sorte de Saussure em relação a uma possível descoberta dos textos manuscritos de Jesus.

Mais pour les Évangelis nous sommes dans l'heureuse situation de ne pas avoir trouvé, post festum, des notes manuscrites de la main de Jésus. Le texte des Évangelis prête déjà assez à des interprétations différentes et à des malentendus terribles. On n'ose pas penser aux guerres de la religion qu'aurait générées la découverte des manuscrits de Jésus. Seraitce qui risque d'arriver autour du Cours de linguistique générale? (TRABANT, 2005, p. 116) 5 .

O autor continua sua comparação do CLG com os possíveis escritos de Jesus, considerando que se trata de dois textos que não foram escritos por aquele a quem se atribui a autoria e, especialmente, as múltiplas interpretações a que tais escrituras se prestam. Jesus, por seu lado, não escreveu senão na areia, e, além disso, os evangelistas que escreveram a bíblia não foram testemunhas diretas e não estavam presentes quando as palavras sagradas foram pronunciadas. Já em relação ao CLG, os editores Charles Bally e Albert Sechehaye também não foram testemunhas oculares dos cursos ministrados por Saussure em Genebra.

\footnotetext{
5 Tradução nossa: "Mas para os evangelistas nós estamos na feliz situação de não ter encontrado, post festum, notas manuscritas da mão de Jesus. O texto dos evangelistas presta-se a muitas interpretações diferentes e a mal-entendidos terríveis. Não ousamos pensar em guerras da religião que teriam gerado a descoberta dos manuscritos de Jesus. Será que corremos o risco disso acontecer em torno do Curso de Linguística Geral?”.
} 
Um outro ponto importante, ao nosso ver, é trazido também por Trabant (2005) quando ele ressalta ainda, não só o problema de interpretação, mas também o problema da multiplicidade das línguas nas versões escritas:

Jésus n'écrit pas, il parle, il parle très problablement en araméen. Les évangélistes écrivent. Mais sauf par "Eli, eli, lama asabthani", seules paroles araméennees retenues (des paroles d'ailleurs, qui ne sont pas adressées aux auditeurs humains mais à Dieu), les évangélistes rapportent les paroles du Christ en $\operatorname{grec}^{6}$ (TRABANT, 2005, p. 116).

Sabemos também que a palavra de Jesus está fadada ao castigo divino da multiplicidade das línguas relatado no mito de Babel no texto bíblico. Aliás, como dissemos anteriormente, a expressão latina vulgata é atribuída ao texto sagrado quando este passa a ser traduzido para o latim no século IV a.C. Cabe ressaltar também que o debate suscitado para que a bíblia fosse traduzida para outras línguas gerou uma fissura na própria religião, dividindo os cristãos entre católicos e protestantes. Essa divisão também gerou uma outra versão da bíblia (que é mencionada de forma sutil no conto de Borges) e, portanto, outra(s) interpretação(ões) da palavra divina.

No tocante às traduções do CLG, não podemos deixar de mencionar também a problemática suscitada, por exemplo, entre a versão americana (de Wade Baskin, 1959) e a versão britânica (de Roy Harrys, 1983) do CLG, em que os tradutores divergem quanto à tradução dos conceitos centrais da teoria saussuriana, a saber, langue, langage et parole. $\mathrm{O}$ castigo da multiplicidade das línguas não poupa nem a palavra sagrada, nem o trabalho do próprio linguista sobre o seu objeto tão escorregadio. Pelo menos o dilema sobre quem veio primeiro não se coloca aos linguistas, não só porque o tema da origem das línguas foi interditado aos linguistas (AUROUX, 2008), mas também porque o próprio texto bíblico se encarrega de afirmar que "no princípio, era o verbo...".

Talvez possa parecer uma digressão à parte, mas o que queremos colocar aqui como mote de nossa reflexão é a natureza complexa do processo de edição do CLG que, assim como o texto sagrado, apesar das intensas discussões, só contribuiu para, ao longo de todos esses anos, consagrar o lugar dessa obra entre os linguistas. Desse modo, é preciso reconhecer também que as sucessivas publicações das notas que serviram de fonte ao CLG e as notas do mestre encontradas posteriormente não mudaram de forma significativa o

\footnotetext{
${ }^{6}$ Tradução nossa: "Jesus não escreve, ele fala, e ele fala muito provavelmente em aramaico. Os evangelistas escrevem. Mas, exceto por 'Eli, eli, lama asabthani', únicas palavras aramaicas retidas (palavras, que, aliás, não são endereçadas aos ouvintes humanos, mas a Deus) os evangelistas reportam as palavras do Cristo em grego".
} 
lugar do CLG na história da Linguística e tampouco colocaram em cheque a problemática acerca da autoria do CLG.

Para nós, essa relação nos faz ver o quanto a língua é resultante da interpretação, o quanto ela está focada na sujeição do editor e do pesquisador quando da leitura, da compreensão e da interpretação de manuscritos de linguistas até a sua edição. O quanto o ponto de vista cria o objeto de circulação e de divulgação. O quanto o sujeito leitor está imerso entre o infinito e sua potência de sentidos, sempre à deriva, mas nunca em qualquer direção. No entanto, a direção tomada por princípios metodológicos e de edição nos leva para a direção do editor, para as suas escolhas, para o seu ponto de vista, criando um novo olhar no mesmo objeto.

\section{A ordem dos fatores altera o produto: o corpus saussuriano}

Unde exoriar? - C'est la question peu prétentieuse, et même terriblement positive et modeste que l'on peut se poser avant d'essayer par aucun point d'aborder la substance glissante de la langue. Si ce que je veux en dire est vrai, il n'y a pas un seul point qui soit l'évident point de départ (SAUSSURE, 2011, p. 281).

O que se convencionou chamar de corpus saussuriano (FIORIN; FLORES; BARBISAN, 2013) é um conjunto de documentos formado por fontes de natureza heterogênea que compreende publicações de Saussure e também aquelas obras publicadas em seu nome, bem como notas manuscritas de Saussure referentes a diversos temas de pesquisa. Entre as obras publicadas em seu nome, tem grande destaque aquela que se tornou (e o tornou) mais célebre: o Cours de Linguistique Générale (CLG).

Como sabemos, o CLG é uma obra póstuma que foi editada e publicada em 1916 por Charles Bally e Albert Sechehaye a partir de notas dos alunos e do mestre genebrino referentes aos cursos ministrados na Universidade de Genebra entre 1907 e 1911. Dada a natureza complexa do processo de edição dessa obra, posteriormente, na década de 1950, algumas notas que serviram de fonte para o CLG (e também algumas notas do mestre encontradas após a publicação) começaram a ser publicadas por Robert Godel, a partir do volume 12 (1954), na Revue Cahiers Ferdinand de Saussure ${ }^{7}$, revista suíça cujo nome diz muito:

\footnotetext{
${ }^{7}$ Disponível em:

$<$ http://www.cerclefdsaussure.org/index.php?option=com_content\&view=article\&id=14:publications-ducercle-ferdinand-de-saussure\&catid=2\&Itemid=133 > . Acesso em: 10 set. 2018.
} 
Cabiers que servem como fontes de estudos também sobre a obra do mestre genebrino. Trata-se de uma publicação editada em colaboração com a Sociedade Genebrina de Linguística e também com o Círculo Ferdinand de Saussure em Genebra. Os manuscritos editados por Godel encontram-se hoje na Bibliothèque de Genève no Fundo Papiers de Ferdinand de Saussure.

Cabe ressaltar também que existe uma outra parte dos manuscritos saussurianos que se encontra hoje na Houghton Library de Harvard University. Esse conjunto de manuscritos foi adquirido por intermédio de Roman Jakobson, que obteve de Raymond e Jacques de Saussure (os filhos do mestre genebrino) uma doação ${ }^{8}$, em 1968. Herman Parret foi um dos primeiros a se dedicar ao estudo dos manuscritos saussurianos de Harvard, publicado, pela primeira vez, em 1993, também na Revue Cabiers, no volume 47.

Historicamente, o legado saussuriano está, principalmente, em notas manuscritas que sequer foram publicadas ou, ao menos, escritas para esse fim. Desse modo, a iniciativa de Bally e Sechehaye ao editarem o CLG e o trabalho pioneiro de Robert Godel nos apontam para a complexidade e amplitude do corpus saussuriano. Como sabemos, posteriormente, ao corpus saussuriano foram acrescidos mais documentos: para a surpresa de todos, em 1996 foram encontrados mais manuscritos de Saussure que foram entregues à Bibliothèque de Genève e somados a outros. Trata-se de um grande conjunto de notas do mestre, 274 folhas mais especificamente, reunidas e classificadas, desta vez, por Rudolf Engler e arquivados na Bibliothèque de Genève no Fundo Archives de Saussure 372.

Uma parte desses manuscritos foi editada e publicada por Rudolf Engler e Simon Bouquet, em forma de livro, cujo título é Écrits de Linguistique Générale (2002), que conta com manuscritos inéditos encontrados em 1996, com destaque especial para o conjunto de notas intitulado "Science du langage", e também manuscritos já editados e publicados anteriormente pertencentes ao Fundo Papiers de Saussure.

Os manuscritos encontrados em 1996 e agrupados no Fundo Archives de Saussure 372 foram (re)editados e publicados em 2011, por René Amacker sob o título Science du langage: de la double essence du langage. René Amacker, na introdução da sua edição, justifica sua

\footnotetext{
8 A problemática sobre a doação/compra dos manuscritos saussurianos é mencionada por Herman Parret, que coloca lado a lado duas versões sobre esse episódio: "R. Jakobson parle d'un don plutôt que d'un achat: «Raymond and Jacques de Saussure generously endowed the Houghton Library of Harvard University with a collection of their father's manuscripts» (R. Jakobson, «Saussure's Unpublished Reflections on Phonemes», in Cabiers Ferdinand de Saussure 26, 1969, 5-14). L'administration de la Houghton Library réfute cette affirmation" (PARRET, 1993, p. 179).
} 
publicação afirmando que seu amigo Rudolf Engler havia lhe confessado o desejo de publicar uma edição crítica de tais manuscritos. A morte prematura de Engler e o interesse da editora francesa Gallimard direcionaram para uma publicação voltada para um público mais amplo. Em respeito ao desejo do amigo, René Amacker publica uma edição crítica, pela editora suíça Droz, como forma de homenagear Rudolf Engler.

Estudando as duas edições, a francesa e a suíça, publicadas referentes aos manuscritos encontrados em 1996, Rastier (2016) considera que:

les deux éditions divergent par leur propos mais demeurent complémentaires. Dans la première, l'absence de notes, l'effacement des repentirs servent l'énergie radicale et la concision de la pensée et favorisent à bon droit la sidération du lecteur, car l'étonnement est on le sait le premier moteur des interprétations créatrices. Dans la seconde, les détails les plus minutieux donnent carrière à des réflexions sur la génétique du texte théorique et appellent une lecture érudite ${ }^{9}$ (RASTIER, 2016, p. 14).

Na edição francesa elaborada por Rudolf Engler e Simon Bouquet cada nota ganha uma numeração e um título atribuído pelos editores. Já na edição elaborada por René Amacker as notas são identificadas, primeiramente, por um número referente à ordem do manuscrito na referida edição; depois, com dois números entre colchetes: o primeiro é referente ao número do envelope do Archive 372, e o segundo número é aquele assinalado a lápis no manuscrito original por Rudolf Engler; e, por fim, há uma terceira marcação entre parênteses que sinaliza onde tal nota se encontra na edição Écrits de Linguistique Générale. Caso a nota não tenha sido editada por Engler e Bouquet, é sinalizada como: pas dans ELG. Cabe ressaltar ainda que, cada uma dessas obras foi editada sob critérios bastante diferentes e a ordem em que as notas foram colocadas é de inteira responsabilidade do(s) editor(es) e não corresponde (necessariamente) à ordem em que se encontram no Fundo.

Segundo Amacker (2011), a classificação atual das notas que constituem o Fundo Archives de Saussure 372 foi atribuída por Rudolf Engler, mas destaca também que "l’ordre des textes dans l'édition Gallimard est légèrement différent; je suppose que les deux éditeurs sont conjointement responsables des changements apportés par rapport au

\footnotetext{
9 Tradução nossa: “As duas edições divergem por seu propósito, mas permanecem complementares. Na primeira, a ausência de notas, o apagamento das correções riscadas servem à energia radical e à concisão do pensamento e favorecem o direito do desconcerto do leitor, porque a admiração é, sabe-se, o primeiro motor das interpretações criativas. $\mathrm{Na}$ segunda, os detalhes os mais minuciosos dão prosseguimento a reflexões sobre a genética do texto teórico e fazem apelo a uma leitura erudita".
} 
classement BGE"10 (AMACKER, 2011, p. 18). No entanto, Rastier (2016, p. 13), por seu lado, acrescenta ainda que 'l'ordre des documents retrouvés n'a pas été conservé: Rudolf Engler les a classés et ordonnés avant de les déposer à la Bibliothèque publique de Genève. Les titres des sections, correspondant à autant d'enveloppes, sont de sa main"11.

De fato, a problemática da ordem se impõe a qualquer pesquisador que se depare com a grande quantidade de notas de naturezas tão diversas que se somam aos documentos já classificados e aqueles ainda por classificar e ordenar. De Mauro (2016, p. 37) afirma, com toda razão, que “il est clair qu'en raison de cette variété de références, ces ELG méritent une certaine attention". Diante desse emaranhado com que se deparam os pesquisadores, De Mauro (2016) atribui um ar poético e mágico ao trabalho desses desbravadores:

Bien entendu, ces matériaux sont en désordre. L'atmosphère générale qui s'en dégage ressemble à celle d'un atelier où travaille l'artiste : parsemé de fragments, de débris, de déchets, d'ébauches; cependant, ici et là, quelque chose de plus fini apparaît, et parfois même, d'admirablement fini : il s'agit en somme d'un désordre à la recherche de l'invention d'un ordre nouveau $^{12}$ (DE MAURO, 2016, p. 37).

Portanto, para De Mauro (2016), o trabalho dos pesquisadores é da mesma ordem que o trabalho do artista e resulta em uma invenção a qual é constituída pela interpretação acerca do corpus que busca apreender e dar ordem. Desse modo, para nós, esses manuscritos, ao serem editados e publicados, estão sujeitos a uma nova ordem atribuída pelo gesto interpretativo do sujeito que se propõe a editá-los.

No entanto, essa inquietação acerca da ordem não é partilhada apenas entre os pesquisadores e editores. Em várias notas, Saussure faz alusão à dificuldade de começar e dar linearidade a sua reflexão, dada a complexidade da natureza do objeto de estudo. Segundo De Mauro (2016),

Saussure lui-même prend position sur le problème de l'ordre et (dironsnous à la manière de Croce, traducteur de Hegel) 'del cominciamento'. C’est

\footnotetext{
10 Tradução nossa: "a ordem dos textos na edição Gallimard é ligeiramente diferente; eu suponho que os dois editores são conjuntamente responsáveis pelas mudanças trazidas em relação à classificação BGE".

11 Tradução: "A ordem dos documentos encontrados não foi conservada: Rudolf Engler as classificou e as ordenou antes de colocá-las na Biblioteca pública de Genebra. Os títulos das seções, correspondente a tantos envelopes, são de sua mão".

12 Tradução: “Certamente, estes materiais estão em desordem. A atmosfera geral que se desprende parece aquela de um ateliê onde trabalha o artista: dispersão de fragmentos, de cacos, de resíduos, de esboços; entretanto, aqui e acolá, alguma coisa de mais acabado aparece, e às vezes, admiravelmente acabado: trata-se, em resumo, de uma desordem à procura de uma invenção de uma ordem nova”.
} 
là une question qui le tourmente, comme elle a tourmenté déjà Pascal et Hegel et également le dernier Wittgenstein aux prises avec ses Investigations philosophiques ${ }^{13}$ (DE MAURO, 2016, p. 37).

Em várias notas manuscritas, deparamo-nos com questionamentos de Saussure acerca do ponto de partida, por onde começar, como veremos mais adiante. Esses questionamentos que atormentavam Saussure, agora atormentam os pesquisadores e editores. É preciso reconhecer que o trabalho de tais pesquisadores é por demais minucioso e cada um, incontornavelmente, carrega seu gesto interpretativo acerca do corpus saussuriano. Entretanto, Sofia (2012) alerta que

En effet, sur un total d'environ 30.000 pages écrites, réparties entre la Bibliothèque de Genève et la Houghton Library de Harvard et relevant projets et périodes hétéroclites, moins d'une dixième partie a été étudiée, éditée et publiée ${ }^{14}$ (SOFIA, 2012, p. 36).

Considerando o volume de notas saussurianas ainda inéditas, entre outros fatores, Sofia $^{15}$ (2012, p. 36) sustenta que “c'est de l'avenir qu'il faut attendre l'apport le plus important des manuscrits saussuriens"16.

\section{Dos prazeres e das angústias na leitura da edição de manuscritos ou o mal-estar do pesquisador diante de um livro de areia:}

Comprovei que as pequenas ilustrações distavam duas mil páginas uma da outra. Fui anotando-as num livreto alfabético, que não demorei a preencher. Nunca se repetiram. De noite, nos escassos intervalos que a insônia me concedia, sonhava com o livro.

Jorge Luis Borges - O livro de areia

Em todas as nossas visitas e consultas ao Fundo Papiers de Saussure e ao Fundo Archives de Saussure na Biblioteca de Genebra, nossa maior preocupação era tentar entender, pela formação positivista que temos no contexto brasileiro, como se poderia organizar algo

13 Tradução nossa: "O próprio Saussure toma posição sobre o problema da ordem e (diremos à maneira de Croce, tradutor de Hegel) 'del cominciamento'. É uma questão que o atormenta, como atormentou já Pascal e Hegel e igualmente o último Wittgenstein com suas Investigações filosóficas”.

14 Tradução: "Com efeito, sobre um total aproximado de 30.000 páginas escritas, divididas entre a Bibliothèque de Genève et la Houghton Library de Harvard, revelando projetos e períodos heteróclitos, menos de um décimo do todo foi estudado, editado e publicado".

15 Cabe ressaltar que Sofia dedicou-se ao estudo das notas de Sechehaye para a elaboração do CLG, a fim de compreender o que ele designa como o processo de colação para a edição do que conhecemos hoje como CLG. A edição proposta por Sofia (2012) constitui-se, de um lado, pela imagem do manuscrito, e, de outro lado, a edição desse manuscrito, conservando os mínimos detalhes do documento original.

16 Tradução: "É do futuro que é preciso esperar uma contribuição mais importante dos manuscritos saussurianos". 
que era da ordem do individual, do subjetivo. Como organizar o rascunho de um pensamento que não era o nosso, como organizar ideias e conflitos que não eram os nossos. Nosso maior lampejo era tentar a toda a prova linearizar algo da ordem do infinito, do interminável. Avesso a qualquer organização possível do ponto de vista contemporâneo. E a modernidade estava ali na sua forma mais concreta. O lápis, a folha de papel, a rasura, o rabisco, o desenho, a representação de algo, enfim o manuscrito na sua forma mais crua, visível sob uma forma geométrica plena de caminhos torcidos, sem fim, sem começo. O mais difícil foi sair da zona de conforto positivista e contemporânea, para tentar alçar voo naquilo que estava posto.

Aos poucos, fomos dando forma à nossa forma de ler, à nossa forma de interpretar, aos poucos, fomos traçando um caminho, fomos ancorando aqui e lá uma certa ordem, uma ordem reversível ao que já havia sido dado. Foi quando nos demos conta de alguns manuscritos que compunham a publicação do ELG e a partir deles fomos construindo o nosso objeto, o nosso trajeto no emaranhado de informações desconexas e contraditórias. Como sabemos no que toca ao corpus saussuriano, especialmente aquelas obras que foram publicadas em nome de Ferdinand de Saussure, a problemática da ordem se impõe por tratar-se de edições de notas dispersas que, por vezes, estavam longe de um texto final.

Começamos por uma das primeiras publicações das notas saussurianas, não porque buscamos a origem, mas para ilustrar que essa problemática acerca da ordem já está posta desde os primeiros trabalhos de exegese de tais manuscritos. Começamos, mais precisamente, por uma declaração do próprio mestre em relação à dificuldade de começar e dar linearidade a um pensamento teórico da dimensão da linguagem. Trata-se de um fragmento da nota numerada como (9) por Robert Godel e publicada no volume 12 da Revista Cabiers. Antes de abordar a nota, é preciso compreender do que essas notas tratam e em que condições elas foram escritas e publicadas.

Como dissemos anteriormente, os manuscritos de Saussure começaram a ser editados e publicados por Robert Godel, em 1954, nos Cabiers. O primeiro conjunto de notas manuscritas de Saussure, publicado no volume 12, é constituído por 23 notas numeradas por Robert Godel. Essas notas foram consultadas pelos editores do CLG, mas descartadas por não serem referentes aos cursos ministrados. No entanto, elas auxiliaram no trabalho de colação elaborado pelos editores do CLG, e Robert Godel, ao editá-las, sinaliza para o leitor onde elas foram retomadas no CLG. Posteriormente foram publicadas 
mais notas inéditas de Saussure por Robert Godel, especialmente no volume 15, dedicado em homenagem ao centenário (de nascimento) de Saussure. Essas notas foram catalogadas, classificadas e arquivadas por Godel na Bibliothèque de Genève no Fundo Papiers Ferdinand de Saussure.

É preciso reconhecer que, em várias notas, Saussure faz alusão à dificuldade de encontrar um ponto de partida, e, por isso, poderíamos ter escolhido qualquer outra. No entanto, deparamo-nos com a nota (9), onde encontramos uma ponderação do mestre acerca do ponto de partida para abordar o objeto, bem como à ordem de estudá-lo:

Il y a donc véritablement absence nécessaire de tout point de départ, et si quelque lecteur veut bien suivre attentivement notre pensée d'un bout à l'autre de ce volume, il reconnaittra, nous en sommes persuadés, qu'il était pour ainsi dire impossible de suivre un ordre très rigoureux .

Nous nous permettrons de remettre, jusqu'à trois et quatre fois, la même idée sous les yeux du lecteur, parce qu'il n'existe réellement aucun point de départ plus indiqué qu'un autre pour y fonder la démonstration ${ }^{17}$ (SAUSSURE, 1954, p. 56-57).

Estima-se que essas notas tenham sido escritas em 1893-1894 e, além disso, é preciso ressaltar que essa nota especificamente é um fragmento de um esboço de livro que estava sendo projetado por Saussure. De fato, o referido livro jamais chegou a ser escrito (e publicado por ele), ainda que tenha sido referido por Saussure inúmeras vezes. Diante dessa nota, Gadet (1987, p. 26) também se questiona acerca da ordem e considera que, de fato,

la question de l'ordre de présentation est donc présente depuis la genèse des réflexions saussuriennes. Si ce point a constitué un problème pour Saussure, puis un problème pur les éditeurs, il n'y a rien d'étonnant à ce que l'ordonnancement de la présentation ait aussi constitué un problème pour nous, dans notre propre travail: quel ordre adopter?18 (GADET, 1987, p. 26).

O questionamento da autora também é o nosso e ainda hoje (várias décadas depois) não temos uma resposta para tal questão, mas, dando continuidade à problemática da edição... a referida nota (9) dos Cahiers foi editada e publicada também na obra ELG junto a

\footnotetext{
17 Tradução nossa: "Há, por isso, verdadeiramente ausência necessária de todo ponto de partida, e se algum leitor quer seguir bem atentamente nosso pensamento de uma ponta à outra desse volume, ele reconhecerá, estamos persuadidos disso, que seria também dizer impossível de seguir uma ordem tão rigorosa. Nós nos permitiremos de remeter, até três e quatro vezes, a mesma idéia sob os olhos do leitor, porque não existe realmente nenhum ponto de partida mais indicado que outro para fundar a demonstração" (CFS, 1954, p. 56-57).

18 Tradução: "a questão da ordem de apresentação está, portanto, presente desde a gênese das reflexões saussurianas. Se esse ponto constituiu um problema para Saussure, depois um problema para os editores, não tem nada de espantoso que essa ordem de apresentação tenha também constituído um problema para nós em nosso trabalho: qual ordem adotar?".
} 
Leitura A problemática acerca da edição das notas saussurianas: um livro sem fim nem comeşo ou um livro de areia à la Borges? Amanda Eloina Scherer, Maria Iraci Sousa Costa

outros documentos designados pelos editores como anciens documents (antigos documentos) e recebeu uma nova referenciação, desta vez, pelos editores Rudolf Engler e Simon Bouquet: 10a [Notes pour un livre sur la linguistique générale, 1] (1893-1894) ${ }^{19}$. Na referida edição francesa, essa nota encontra-se na página 197. Essa nota não pode ser localizada na edição suíça de René Amacker, pois nessa publicação só foram editados os manuscritos do Fundo Archives de Saussure 372 e a referida nota pertence ao conjunto de documentos Papiers Ferdinand de Saussure.

Quando comparamos uma nota com a outra em ambas as edições, no Cabiers e no ELG, reparamos que elas coincidem somente em uma primeira parte, de modo que, numa segunda parte, a sequência do texto toma um caminho diferente. Para ilustrar ao nosso leitor, comparamos aqui a nota editada (figuras 1 e 2), mais especificamente no momento em que as edições se distanciam e o texto acaba se tornando outro:

${ }^{19}$ Sobre essa nota, cabe ainda mais uma observação: na versão brasileira da obra Écrits de Linguistique Générale (ELG), no início da nota, há um problema de tradução. Na obra ELG, assim como na revista CFS, temos o seguinte: "comme le langage n'offre sous aucune de ses manifestations une substance" (SAUSSURE, 2002, p. 197; 1954, p. 55), enquanto, na versão brasileira temos "como a língua não oferece, sob nenhuma de suas manifestações, uma substância” (SAUSSURE, 2012, p. 170). Como sabemos, langue et langage/língua e linguagem não são sinônimos na obra de Saussure e langage não poderia ser traduzida como língua. Precisaríamos um estudo mais aprofundado de tal tradução para entendermos melhor as suas razões. 


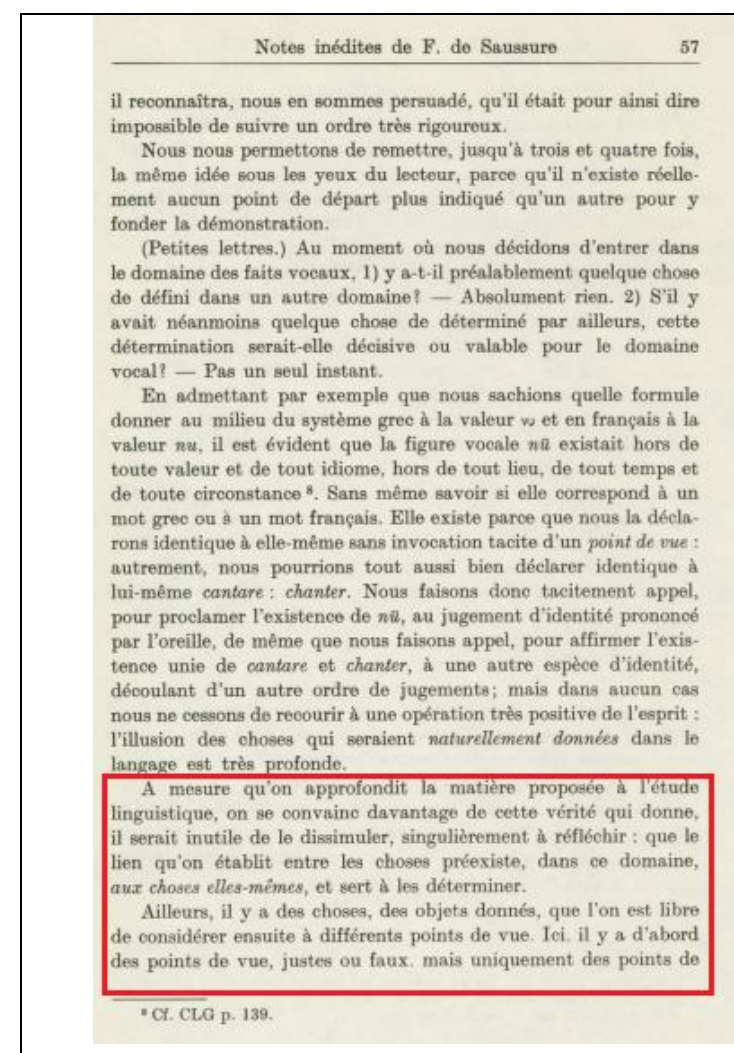

Figura 1: manuscrito de Saussure. Fonte: Saussure, 1954, p. 57.
Anciens documents

cantâre : chanter. Nous faisons donc tacitement appel, pour proclamer l'existence de nü, au jugement d'identité prononcé paristence unie de cantàre et chanter, à une pour affirmer

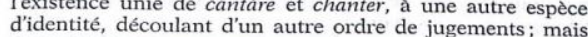
dans aucun cas nous ne cessons de recourir a unents; mais très positive de l'esprit : l'illusion des choses qui seraient naturellement données dans le langage est profonde. Premiere maniere de raisonner: «Il y a le latin cantäre ». Et cantāre, « au point de vue de » la figure vocale qu'il représente, est identique à tel mot cafre ou samoyède; « au point de vue de " la continuation régulière de cette figure, est identique au français chanter; "au point de vue de " sa valeur en latin [ ] ]

On s'aperçoit alors que, pour considérer successivement cantäre à tant de points de vue, qui en font des choses toutes différentes, la première condition serait de savoir en quoi consiste le véritable cantāre, où est la garantie de son existence, ou simplement la forme solide de son existence. C'est ici qu'on est conduit à la :

Deuxième manière de raisonner : nous reconnaissons en effet qu'on ne peut dire : "Il y $a$ un latin cantāre » parce qu'il est absolument impossible de savoir de quoi il s'agit hors d'un point de vue qu'il faut choisir Nous choisirons donc un point de vue qui nous fournira une base ferme. Nous úćclarons formellement que cantāre est pour nous la figure vocale kan-tā-re; tout ce qui s'ajoutera sera attribut.

vocale kan-ta-re, tout ce raisonner, pour nous seule admissible :

Il ' n'y a rien, c'est-à-dire non seulement rien qui soit déterII ne d' miné davance hors diqué que les autres.

rl vui soit plus indique que comparative des points de

Il n'y a dabord que la critique compar d'un latin cantōe de

vue. Dire qu'on n'a pas le rait ridicule ou au contraire d'une évidence ridicule.

évidence ridicule.

\begin{tabular}{ll|l}
$\begin{array}{l}\text { identité } \\
\text { identité }\end{array}$ & $\begin{array}{l}\text { cantāre } \\
\text { cantāre } \\
\text { sens et emploi } \\
\text { cantāre }\end{array}$ & $\begin{array}{l}\text { cantāre } \\
\text { cantāre } \\
\text { sens et emploi } \\
\text { chanter }\end{array}$ \\
identité & chanter
\end{tabular}

Figura 2: manuscrito de Saussure. Fonte: Saussure, 2002, p. 199.

Ainda que se trate da mesma nota, a linearidade do texto desdobra-se em outra possibilidade e o texto se transforma em outro. Em nenhuma das edições há qualquer sinalização ao leitor de qualquer percalço que o editor possa ter encontrado. Aqueles que buscam um Saussure autêntico ou verdadeiro nas notas saussurianas editadas novamente se deparam com o problema já apontado no texto vulgata. O que nos inquieta é que voltamos mais uma vez àquela mesma problemática já colocada em relação ao trabalho dos editores do CLG. De fato, como os editores afirmam no prefácio, o CLG é uma reconstrução com base no terceiro curso. Nessa edição das notas na revista Cabiers, trata-se de uma publicação das notas sem vistas a uma reconstrução ou a um preenchimento das lacunas do texto. $\mathrm{O}$ que colocamos como questionamento entre esses dois textos possíveis é: o que aconteceu nesse intervalo entre ambas edições para que essa nota tenha se tornado outra? Como sair desse labirinto e encontrar uma ordem? Mas qual ordem? Onde está Ariadne para nos dar o fio que nos levaria para fora desse labirinto?

De todo modo, o exemplo dessa nota nos aponta para a complexidade do trabalho dos pesquisadores e editores que buscam um ponto de partida e também de continuidade nesse emaranhado de notas. Mesmo classificadas e editadas, nada nos assegura que uma 
Leitura A problemática acerca da edição das notas saussurianas: um livro sem fim nem começo ou um livro de areia à la Borges? Amanda Eloina Scherer, Maria Iraci Sousa Costa

ordem seja preferível à outra. Em meio ao conjunto de notas, essa nota, em cada edição, ganha um lugar possível de acordo com a interpretação do editor. Entretanto, a dúvida que paira é em relação à ordem que o autor das notas teria dado... isso não saberemos jamais, uma vez que essa também parecia ser a dúvida do próprio Saussure à procura de um começo.

Um outro exemplo sobre a problemática da ordem, agora considerando as edições publicadas em 2002 e 2011, pode ser ilustrado com a nota numerada e nomeada por Rudolf Engler e Simon Bouquet na obra ELG como "21 [Identification, Valeurs relatives, Points de vue]", a qual se encontra nas páginas 66 e 67. Essa nota corresponde às notas manuscritas originais numeradas a lápis (por Rudolf Engler) p. 134, p. 135 e p. 136 referentes ao Fundo Archives de Saussure 372. Na obra Science du Langage, editada por René Amacker, essa nota recebeu o número 59 e encontra-se nas páginas 124, 125 e 126. Para ilustrar ao nosso leitor, colocamos lado a lado as edições (figuras 3 e 4): a primeira sinalizando onde uma nota foi somada a outra dando uma provável linearidade ao texto, e a segunda sinaliza a forma como a nota foi editada dando outra ordem à textualidade. Vejamos: 


\begin{abstract}
66 De l'essence double du langage

ordre. Nous nions au contraire qu'aucun fait de langue, depuis [ ] n'existe un seul instant pour lui-même hors de depuis [ ] nowiste d'autres, et qu'il soit autre chose qu'une son opposition avec dautres, et quil so résumer un ensemble manière plus ou moins heureuse de résumer un différence de différences en jeu : de sorte que seules ces differences existent, et que par là même tout l'objet sur lequel porte la science du langage est précipité dans une sphère de relativité, sortant tout à fait et gravement de ce qu'on entend d'ordinaire par la « relativité » des faits.

A leur tour ces différences en lesquelles consiste toute la A leur tour ces differaient rien, n'auraient pas même de langue ne représenteraient rien, nauraient pas me de sens en telle matière, si l'on ne voulait dire par la : ou bien la différence des formes (mais cette différence n'es rien), ou bien la différence des formes aperçue par l'esprit (ce qui est quelque chose, mais peu de chose dans la langue) (ce qui est quelque chose, résultent du jeu compliqué et de l'équilibre final.

l'équilibre final.

Ainsi non seulement il n'y aura pas de termes positifs mais des différences; mais deuxièmement ces différences

Comme quoi fait de langue demande séparation entre les points de vue diachronique et synoptique.
\end{abstract}

\section{1 [Identification; Valeurs relatives, Point de vue]}

Nous reconnaissons l'identité morphologique (qui est nécessairement dans deux langues déterminées);
[1] l'identité selon l'analyse
morphologique :
alka alka
[2] sens de
palka empi-alka

et enfin l'identité selon la succession possible qui crée l'iden-

tité dans le temps $\left\{\begin{array}{l}\text { arka }{ }^{1} \\ \text { alka } \\ \text { auka } \\ \bar{o} k a \\ \bar{o} k\end{array}\right.$

1. Seul arke, dans ce paradigme, est un mot sanscrit. (N.d.E.)
De l'essence double du langage

67

En revanche nous nierons toujours qu'il $y$ ait un sens a parler de alka, qu'il y ait quelque chose qui soit alka hors d'une de ces opérations sous-entendues d'identification. Elle suppose immédiatement l'élection d'un point de vue : Elle cette élection, les identifications possibles restent multiples, et il s'ensuit que la formule alka ne représente littéralement rien.

De la même façon que dans le jeu d'échecs il serait absurde de demander ce que serait une dame, un pion, un four, un cavalier, si on le considérait hors du jeu d'échecs, de même façon i langue, à chercher ce qu'est chaque élément par lui-même. Il n'est rien d'autre qu'une pièce valant par son opposition avec d'autres selon certaines conventions.

S'il n'y avait pas ce fait en somme contingent que les matériaux de la langue se transforment et entraînent par leur seul changement une métamorphose inévitable des conditions mêmes du jeu, il ne serait pas nécessaire, et on n'urmit jamais songé à jamais songe a scruter la nature exacte de ces matériaux : serait une peine très positivement inutile.

Pour comprendre la transformation des différentes pièces grâce au temps, il devient utile de les analyser en ellesmêmes. Ce n'est pas ce que nous voulons faire ressortir, mais plutôt que dans chaque époque il n'y a que des oppositions, des valeurs RELATIVES (en réalité même conventionnelles, mais se fondant avant tout sur la possibilité d'opposer deux termes en leur conférant deux valeurs).

Les en tant que, les au point de vue de font fort réfléchir en linguistique. Ailleurs il y a une limite aux façons diverses d'envisager les choses, qui est donnée par les choses mêmes. En linguistique on peut se demander si le point de vue où on envisage la chose n'est pas toute la chose, et par conséquent en définitive si nous partons sur un seul point de quelque chose de concret, ou s'il n'y a jamais eu autre chose que nos points de vue indéfiniment multipliables.

\section{2a [Phonétique et morphologie]}

Phonétiquement, ou dans le domaine des figures vocales, $\mathrm{i}$ y a une limite exte et absolue entre l'altération indéfinie d'une figure et l'anéantissement parfait de cette figure.

Figura 3: nota 21 do ELG. Fonte: SAUSSURE, 2002, p. 66-67.

Exemple. Si je choisis 'pour entrer dans l'étude du langage le procédé de simplification maximum, qui consiste à ${ }^{2}$ supposer que le langage soit une ${ }^{3}$ succession $\left[{ }^{4}\right.$

\section{9. [3.95] (ELG p. 67)}

La ${ }^{5}$ situation particulière du 'linguiste vis-à-vis de l'objet qu'il étudie peut être caractérisée par cette remarque :?

Lorsque nous nous efforçons de ${ }^{8}$ préciser en disant, non plus simplement ceci ou cela, mais ceci « en tant que...»; cela « au point de vue de " (par exemple legere comme infinitif, $\Gamma^{9}$

- bien loin que l'esprit ${ }^{10}$ soit satisfait, il est conduit à se demander à quel moment on pourrait cesser, sur un point quelconque d'une langue quelconque, d'user ${ }^{11} d e{ }^{12} c e s$ en tant que... et ${ }^{13}$

\{Remplacer par : $\}^{14}$

Les en tant que, les au point de vue de font fort réfléchir en linguistique. Ailleurs il y a une limite ${ }^{15}$ aux façons ${ }^{16}$ diverses d'envisager les choses, qui est donnée par les choses ${ }^{17}$ mêmes. En

Figura 4: nota 39, Science du Langage. Fonte: Saussure, 2011, p. 89. 
De todo modo, cabe destacar que nenhuma das notas corresponde a mesma ordem em qualquer das edições. Essa nota, especificamente, destaca-se por, na verdade, comportar uma outra nota na edição francesa, onde o último parágrafo dessa nota constitui uma nota independente e distante daquela na qual foi acrescida. O último parágrafo da nota 21 do ELG corresponde à nota 39 da obra Science du Langage, enquanto nos manuscritos originais a referida nota recebeu a numeração 95, anterior e distante da nota que a introduz numerada nos originais como p. 134.

Cada uma das edições baseia-se em critérios distintos para a publicação das notas saussurianas. Quanto ao critério da ordem das notas, especificamente, os editores não mencionam exatamente quais foram os critérios adotados para a edição das notas dispersas. Mesmo nos cadernos de Saussure encontrados não é possível estabelecer uma linearidade de seu pensamento, o que temos, de fato, é uma espécie de ruminação (FENOGLIO, 2013) de um possível pensamento. Os cadernos frequentemente trazem páginas em branco que são lacunares e que, por vezes, são preenchidas (por vezes não). É preciso também considerar a possibilidade de essas possíveis "lacunas" ainda não terem sido preenchidas, porque o conjunto de manuscritos ainda não foi explorado na sua totalidade. Não descartamos também a impossibilidade de encontrar um começo desses manuscritos, uma vez que, por vezes, nem o próprio mestre genebrino o havia encontrado, pois ele não hesita em "começar" suas anotações na ordem em que lhe ocorrem, deixando um espaço vazio para voltar e estabelecer um possível começo.

São vários os pesquisadores que se interessam pelos manuscritos e sobre suas edições e que destacam a problemática de suas publicações. Rastier (2016) inclusive afirma que a publicação de manuscritos póstumos colocou inúmeros problemas de ordem filológica, hermenêutica e linguística e que muitos deles não conseguiram ser resolvidos até o momento. E Sofia (2012) também faz uma crítica às sucessivas edições dos mesmos manuscritos saussurianos publicados até então, uma vez que a falta de critérios bem definidos, segundo o autor, para a edição de um texto manuscrito e as sucessivas (re)edições faz com que os pesquisadores voltem-se frequentemente para o texto original editado, questionando, desse modo, o gesto interpretativo do sujeito editor. Mais, precisamente, o autor considera que

Les critères philologiques adoptés par les éditeurs de ces publications étant différents, les versions résultantes ne sont naturellement pas toujours conformes, et le chercheur les consultant a, donc, à bon droit, de quoi se sentir déboussolé. Ce désordre, uni au déséquilibre signalé 
plus haut (90\% de manuscrits inédits), réclame, et ce de manière urgente, une édition scrupuleuse, intégrale et homogène de la totalité des manuscrits saussuriens ${ }^{20}$ (SOFIA, 2012, p. 37).

Como vemos, embora a problemática acerca da edição dos manuscritos saussurianos não seja recente, ela continua ainda na ordem do dia e coloca problemas aos pesquisadores e editores, os quais ainda estão longe de serem resolvidos. Nesse artigo, não visamos apontar apenas os problemas nas edições numa busca incessante pelo Saussure verdadeiro, mesmo porque, como vimos, jamais encontraríamos o Saussure verdadeiro nas edições de seus manuscritos. Para nós, do ponto de vista materialista, o verdadeiro não existe, o que existe é um real possível na margem de um simbólico.

Desde que o personagem de Saussure foi criado a partir do CLG, lançamo-nos em busca de Ferdinand de Saussure (ARRIVÉ, 2010) quando este já não podia mais ser encontrado. Por vezes, contentamo-nos com um espectro ou uma imagem aproximativa e (de)formada que encontramos naquilo que nos dizem ser Saussure e/ou de Saussure. Por vezes, lançamo-nos em busca por aprimorar e tornar mais nítida a imagem que temos daquilo que acreditamos ser Saussure... mas é preciso lembrar que vai ser sempre uma imagem ou ainda uma miragem (PAVEL, 1990). Se a língua é inatingível (e ela o é!), lidamos eternamente com o desconforto de não ter um ponto de partida a priori que permita abordá-la, como já tentava nos conformar (e conformar a si mesmo) o mestre genebrino. Aceitamos o fato de que a língua nos escapa e também o legado dos manuscritos saussurianos, cujas edições parecem colocar uma imagem de Saussure ao nosso alcance, para logo revelar-se uma miragem. Essa instabilidade das edições dos manuscritos, especialmente no que toca à ordem, nos encaminha para aquilo que Borges chamou de livro de areia... um livro sem começo nem fim, cujas páginas escapam entre nossos dedos e recusam a ordem, impedindo de serem lidas mais de uma vez.

\footnotetext{
20 Tradução nossa: "Os critérios filológicos adotados pelos editores dessas publicações sendo diferentes, as versões resultantes não estão, naturalmente, sempre em conformidade, e o pesquisador as consultando tem, portanto, direito de se sentir desorientado. Esta desordem, une ao desequilíbrio sinalizado anteriormente ( $90 \%$ de manuscritos inéditos), reclama e, de maneira urgente, uma edição escrupulosa, integral e homogênea da totalidade dos manuscritos saussurianos".
} 


\section{À guisa de conclusão}

Os homens costumam inferir desse espelho que a Biblioteca não é infinita (se o fosse realmente, para quê essa duplicação ilusória?), prefiro sonhar que as superficies polidas representam e prometem o infinito...

Jorge Luis Borges - A biblioteca de Babel

Dada essa natureza dispersa dos manuscritos, a ausência de um (possível) começo e um final incerto, ousamos considerar a publicação das edições dos manuscritos saussurianos como uma espécie de livro de areia, no sentido de Borges. As edições das notas manuscritas de Saussure serão sempre uma possibilidade, uma versão, uma vez que, ainda que sejam adotados critérios bem definidos, estarão sempre permeadas pelo gesto interpretativo do sujeito editor. Os começos e os fins são determinados a partir de horizontes de retrospecção e de projeção (AUROUX, 1992), que dependem do ponto de vista do sujeito editor, o qual tem como limite o alcance do seu ponto de vista. Saussure parece flanar, perdido em seus pensamentos, nesse horizonte, sempre à nossa vista, mas nunca ao nosso alcance.

Tratando-se de um livro de areia, é preciso ter sempre o cuidado de lê-lo atentamente, pois pode ser que tal leitura não seja mais posta em uma próxima vez. E certamente não será, pois Borges, por meio do conto do livro de areia, já tentava nos alertar, fazendo alusão ao filósofo Heráclito, que, numa segunda vez, já não seremos mais os mesmos, tampouco a leitura que faremos do livro de areia não o será.

Tal como um livro de areia, a edição das notas manuscritas saussurianas, presta-se, a cada leitura, a uma outra interpretação. O que esboçamos no presente texto é também um trajeto possível na interpretação possível de duas edições, uma por demais conhecida no contexto brasileiro e a outra não tanto. $\mathrm{Na}$ verdade, as duas tratam do mesmo e eterno texto por demais conhecido, mas nunca esgotado ou ultrapassado. E se o nosso leitor conseguiu chegar até aqui sem perder-se nos labirintos de nossa escrita, esperamos apenas que o presente texto não se feche sobre si mesmo, mas possibilite ao nosso leitor ainda outras reflexões. 


\section{Referências}

AMACKER, René. Avant-propos et Introduction. In.: Saussure, F. de. Science du langage - De la double essence du langage. Édition des Écrits de linguistique générale établie par René Amacker. Genève: Librarie Droz, 2011.

ARRIVÉ, Michel. Em busca de Ferdinand de Saussure. Trad. Marcos Marcionilo. São Paulo: Parábola Editorial, 2010.

AUROUX, Sylvain. A revolução tecnológica da gramatização. Campinas: Editora da Unicamp, 1992.

A questão da origem das línguas, seguido de A historicidade das ciências. Trad. M. P. G. Joanilho. Campinas: RG, 2008.

BORGES, Jorge Luis. O livro de areia. Disponível em: $<$ http://varaldeleitura.blogspot.com.br/2013/07/conto-o-livro-de-areia-de-jorgeluis.html>. Acesso em: 10 set. 2018.

CAMARGO, Iberê. Gaveta dos guardados. São Paulo: Cosac Naify, 2009.

DE MAURO, Tullio. F. De Saussure, Écrits de Linguistique Générale, Introduction. In: RASTIER, François (Org.). De l'essence double du langage et le renouveau du saussurisme. Paris: Lambert-Lucas, 2016.

FENOGLIO, Irène. Manuscritos de linguistas e genética textual. Quais os exemplos para a Ciência da Linguagem? Exemplos através dos papiers de Benveniste. Série Cogitare, $n^{\circ}$ 11. Santa Maria: PPGL Editores/UFSM, 2013.

FIORIN, José Luiz; FLORES, Valdir do Nascimento; BARBISAN, Leci Borges (Org.). Saussure: a invenção da Linguística. São Paulo: Contexto, 2013.

GADET, Françoise. Saussure: une science de la langue. Paris: Presses Universitaire de France, 1987.

PARRET, Herman. Les manuscrits saussuriens de Harvard. Revue Cahiers Ferdinand de Saussure, v. 47, p. 179-234, 1993. Disponível em:

<http://www.cerclefdsaussure.org/download/cfs_pdf/Volume_47_1993.pdf >. Acesso em: 10 set. 2018.

PAVEL, Tomas. A miragem linguística: ensaio sobre a modernização intelectual. Trad. E. Orlandi, P. de Souza e S. S. Guimarães. Campinas: Pontes, 1990.

PUECH, Christian. O "discurso", as heranças e os destinos de Saussure na França. In: CRUZ, Marcio; PIOVEZANI, Carlos; TESTENOIRE, Pierre-Yves (Org.) Saussure, o texto e o discurso: cem anos de heranças e recepções. São Paulo: Parábola Editorial, 2016.

RASTIER, François. De l'essence double du langage, um projet révélateur. In: (Org.). De l'essence double du langage et le renouveau du saussurisme. Paris: Lambert-Lucas, 2016. 
Leitura A problemática acerca da edição das notas saussurianas: um livro sem fim nem começo ou um livro de areia à la Borges? Amanda Eloina Scherer, Maria Iraci Sousa Costa

SAUSSURE, Ferdinand de. Notes inédites de F. de Saussure (éditées par Robert Godel). Revue Cahiers Ferdinand de Saussure, v. 12, p. 49-71, 1954. Disponível em: $<$ http://www.cerclefdsaussure.org/download/cfs_pdf/Volume_12_1954.pdf >. Acesso em: 10 set. 2018.

Écrits de linguistique générale. Organisés et édités par Simon Bouquet et Rudolf Engler. Paris: Gallimard, 2002.

Curso de Linguística Geral. 27 ed. Organizado e editado por Charles Bally e Albert Sechehaye. São Paulo: Cultrix, 2006.

Science du langage - De la double essence du langage. Édition des Écrits de linguistique générale établie par René Amacker. Genève: Librarie Droz, 2011.

Escritos de Linguística Geral. Organizados e editados por Simon Bouquet e Rudolf Engler. São Paulo: Cultrix, 2012.

SOFIA, Estanislao. Quelques problèmes philologiques posés par l'œuvre de Ferdinand de Saussure. Langages, $n^{\circ} 185$, p. 35-50, 2012. Disponível em: <https://www.cairn.info/revue-langages-2012-1-page-35.htm>. Acesso em: 10 set. 2018.

TRABANT, J. Faut-il défendre Saussure contre ses amateurs? Notes sur l'etymologie saussurienne. Langages, $\mathrm{n}^{\mathrm{o}}$ 159, p. 111-124, 2005. Disponível em: <http://www.persee.fr/doc/lgge_0458-726x_2005_num_39_159_2655>. Acesso em: 10 set. 2018. 
Leitura A problemática acerca da edição das notas saussurianas: um livro sem fim nem comeso ou um livro de areia à la Borges? Amanda Eloina Scherer, Maria Iraci Sousa Costa

\section{Abstract}

The present article develops a reflection on the complex process of editing the saussurian manuscripts. From the comparative study of Ferdinand de Saussure's notes published in different editions, for example, the notes edited by Robert Godel and published in the Cabiers (1954) journal, the notes edited by Simon Bouquet and Rudolf Engler (SAUSSURE, 2002) and the notes edited by René Amacker (2011), we maintain that each edition published is a book of sand, in the poetic and metaphorical sense attributed by Borges. Each one of these publications of saussurian handwritten notes presents an order that is its own, assigning to the text a singular linearity. As we know, only a small part of the Saussurian manuscripts has been edited and published, and even this small part unfolds in successive (re-) editions, each giving a new/another (re-)arrangement, which makes us reflect on of the order and (im)possible linearity of the Saussurian notes in relation to the criteria given by its editors.

Keywords: Book of sand. Saussurian manuscripts. Editions

Recebido em: 30/04/2018.

Aceito em: 17/05/2018. 